\title{
Impact of Corticosteroids and Anticoagulant Combined Treatment on Patients Affected by COVID-19 Pneumonia
} \author{
Bisogni ${ }^{2 \#}$ and Giacomo Pucci ${ }^{2 \#}$ \\ ${ }^{1}$ ASST Valtellina and Alto Lario, Eugenio Morelli Hospital, Sondalo (SO), Italy \\ ${ }^{2}$ University of Perugia, Terni University Hospital, Terni, Italy \\ ${ }^{\#}$ Authors contributed equally to this study
}

Fabio Anastasio ${ }^{1 *}$, Elisa Scarnecchia ${ }^{1}$, Sarah Barbuto ${ }^{1}$, Fabio Spitaleri ${ }^{1}$, Tommaso Saporito $^{1}$, Valeria

\begin{abstract}
Background: The pathogenesis of novel coronavirus disease (COVID-19) includes virus-induced systemic endothelial dysfunction, cytokine storm, and complement cascade hyperactivation, creating massive inflammatory and pro-coagulative states with diffuse vascular thrombosis.
\end{abstract}

Objective: Our observational cohort study analyzed the effectiveness of corticosteroids and anticoagulant combined treatment in patients affected by COVID-19.

Design and patients: 423 patients were retrospectively included in the analysis. Patients were divided into four groups: Group $1(\mathrm{G} 1, \mathrm{n}=135)$ : No treated; group $2(\mathrm{G} 2, \mathrm{n}=8)$ : Treated by methylprednisolone; group $3(\mathrm{G} 3, \mathrm{n}=214)$ : Those received low-molecular-weight heparin $(\mathrm{LMWH})$; group $4(\mathrm{G} 4, \mathrm{n}=66)$ : Patients treated with combined methylprednisolone plus LMWH. The study outcome was the treatment failure, defined as all-cause of death or Intensive Care Unit (ICU) admission.

Results: Mortality and ICU admission rates were $20.6 \%$ and $15.1 \%$, respectively. The per-group analysis showed an increased prognosis for $\mathrm{G} 3(\mathrm{HR} 0.59,95 \% \mathrm{Cl} 0.36-0.95, p=0.03)$ and $\mathrm{G} 4(\mathrm{HR} 0.47,95 \% \mathrm{Cl} 0.27-0.82, p=0.007)$ vs. non-treated group (G1). Combined therapy was especially successful in those patients with the worst respiratory function $\left(\mathrm{SpO}_{2} /\right.$ $\mathrm{FiO}_{2}$ ratio $\left.\leq 220\right)(\mathrm{HR} 0.43,95 \% \mathrm{Cl} 0.24-0.77, p=0.004)$

Conclusions: LMWH treatment alone and/or in combination with methylprednisolone seems to be associated with a better outcome, reducing the rate of treatment failure in patients affected by COVID-19 pneumonia.

\section{Keywords}

COVID-19, SARS-CoV-2, Pneumonia, Corticosteroids, Low-molecular-weight heparin

\begin{abstract}
Abbreviations
ALP: Alkaline Phosphatase; ALT: Alanine Transferase; APTT: Activated Partial Thromboplastin Time; ARDS: Acute Respiratory Distress Syndrome; AST: Aspartate Aminotransferase; BMI: Body Mass Index; BNP: B-Type Natriuretic Peptide; CI: Confidence Interval; CKD: Chronic Kidney Disease; COPD: Chronic Obstructive Pulmonary Disease; COVID: Coronavirus Disease; CRP: C-Reactive Protein; CVD: Cardiovascular Disease; DM: Diabetes Mellitus; FIO2: Fraction of Inspired Oxygen; Gamma-Gt: Gamma-Glutamyltransferase; HR: Hazard Ratio; HRCT: High Resolution Computed Tomography; ICU: Intensive Care Unit; II-1ß: Interleukin-1B; II-6: Interleukin-6; II-8: Interleukin-8; INR: International Normalized Ratio; IQR: Interquartile Range; I.V.: Intravenous; LDH: Lactate Dehydrogenase; LMWH: Low-MolecularWeight Heparin; MOF: Multi-Organs Failure; N/L: Neutrophils/Leucocytes Ratio; PCR: Polymerase Chain Reaction; PCT: Procalcitonin; PMN: Polymorphonuclear Leukocytes; PT: Prothrombin Time; RR: Respiratory Rate; SARS-Cov-2: Severe Acute Respiratory Syndrome Coronavirus 2; SOFA: Sequential Organ Failure Assessment; SPO2: Peripheral Capillary Oxygen Saturation; SPO2/FIO2: Oxygen Saturation to Fraction of Inspired Oxygen Ratio; TNF-A: Tumor Necrosis Factor-A; VIF: Variance Inflation Factor; WHO: World Health Organization.
\end{abstract}

\section{Introduction}

In March 2020, the World Health Organization (WHO) declared the 2019 novel coronavirus disease (COVID-19) caused by the severe acute respiratory syndrome coronavirus 2 (SARS-CoV-2), a public health emergency of international concern [1-4]. The viral infection can lead to pneumonia, severe acute respiratory syndrome (ARDS), multi-organ fail- 
Citation: Anastasio F, Scarnecchia E, Barbuto S, et al. (2021) Impact of Corticosteroids and Anticoagulant Combined Treatment on Patients Affected by COVID-19 Pneumonia. Res Rev Infect Dis 4(1):125-137

ure (MOF), and even death in the most severe cases [5]. The pathogenesis of COVID-19 disease is dominated by an acute pneumonic process characterized by diffuse alveolar damage, inflammatory infiltrates, and microvascular thrombosis, configuring an ARDS $[6,7]$. Consequent MOF would appear secondary to the massive host immune response and the inflammatory organ injury, with markedly and persistently elevated inflammatory markers such as procalcitonin (PCT), serum ferritin, erythrocyte sedimentation rate (ESR), C-reactive protein (CRP), fibrinogen, D-dimer, lactate dehydrogenase (LDH), and tumor necrosis factor-alpha (TNF- $\alpha$ ), interleukins $1 \beta, 6$, and 8 (IL-1 $\beta, I L-6, I L-8)[1,8,9]$. These latter are able to promote a procoagulant state by the activation of platelets, vascular endothelial cells, and the expression of tissue factor [10], associated with an increased risk of thromboembolic complications (e.g., micro-thrombosis, large vessel thrombosis) with a progressive elevation of D-dimer in function of the severity and extent of thrombosis [11-13]. Hence, several therapeutic interventions have been proposed to mitigate the inflammatory organ injury in viral COVID-19 disease and, consequently, to reduce the hypercoagulable state [13]. Anticoagulant therapy for the management of patients with pneumonia from SARS-CoV-2 infection is widely discussed [10,14-17]; recent retrospective studies seem to show a positive effect on the prognosis $[10,14,18-21]$. Moreover, current trials also showed the improvement of clinical outcomes due to the administration of corticosteroids in critical patients [22-27]. However, in viral COVID-19 pneumonia patients, data on the associated and simultaneous treatment with corticosteroids plus anticoagulant are still under evaluation [28].

Consistently with the hypothesis of a combined beneficial outcome with regard to the reduction of the state of hypercoagulability and inflammation respectively, the aim of our study was to evaluate the effectiveness of low-molecular-weight heparin (LMWH) associated with the administration of corticosteroid (e.g., methylprednisolone) in the management of COVID-19 infected patients with pneumonia, in terms of reducing all-cause mortality and Intensive Care Unit (ICU) admission.

\section{Materials and Methods}

\section{Study design}

All symptomatic suspected COVID-19 patients admitted at the "Eugenio Morelli Hospital" of Sondalo (SO), Lombardy, Italy, in a period between March $3^{\text {rd }}$ and June $3^{\text {rd }}, 2020$ were considered as showed in the Flow-chart of the study (Figure 1). Data were collected from the electronic medical records and retrospectively analyzed. Written informed consent was waived in light of the urgent need to collect data.

Inclusion criteria were: 1) Patients aged > 18-years-old, with COVID-19 diagnosis confirmed by positive results of polymerase chain reaction (PCR) on nasal and pharyngeal swab or on alveolar-bronchiole washing in case of double negative swab [1], and 2) Patients hospitalized to COVID-19 Department for about 24 hours before ICU admission and/or death for all causes, or eventually discharged.

We did not consider in our collection data from (exclu- sion criteria): 1) Patients still hospitalized at the time of the analysis (i.e., $3^{\text {rd }}$ June 2020); 2) Subjects with incomplete clinical and/or biochemical data; 3) Patients who were directly admitted to the ICU for the severity of clinical conditions; 4) Patients who received other treatments, such as tocilizum$\mathrm{ab}$, anakinra, and convalescent plasma therapy, this latter not available in our Hospital.

\section{Data source and variables assessed}

We collected demographic and anthropometric variables, comorbidities, past medical and pharmacological history for all patients meeting the inclusion criteria. Clinical symptoms or signs of COVID-19 disease and laboratory findings at baseline were also evaluated. Laboratory assessments consisted of a complete blood count, blood chemical analysis, coagulation testing, assessment of liver and renal function, measures of electrolytes, CRP, PCT, LDH, cardiac enzymes, high-sensitivity (HS) troponin I, B-type natriuretic peptide (BNP), and urine sample. Radiologic assessments included chest radiography and/or high-resolution computed tomography (HRCT).

For all patients, at the baseline, we also calculated the Charlson index score [29], the Sequential Organ Failure Assessment (SOFA) score [30], haemogasanalytic parameters, including the oxygen saturation to fraction of inspired oxygen $\left(\mathrm{SpO}_{2} / \mathrm{FiO}_{2}\right)$ ratio $[31,32]$.

During the hospitalization, we extracted and analyzed data on administered therapies such as LMWH and methylprednisolone. LMWH was administered at prophylaxis dose for deep vein thrombosis (4,000 IU subcutaneously per day) [25] for at least 14 days. The intravenous (i.v.) administration of methylprednisolone dose, alone or combined with LMWH, was between 0.5 and $1 \mathrm{mg} / \mathrm{kg}$ per day for at least 7 days.

\section{Study outcome}

Considering the paucity of data published so far on the combined treatment with corticosteroids plus anticoagulant in the management of patients affected by COVID-19 pneumonia, the main scope of our study was to evaluate the effectiveness of LMWH associated with the administration with methylprednisolone in terms of reduced all-cause mortality and ICU admission rates of COVID-19 pneumonia cases.

The primary endpoint was the treatment failure rate, defined as ICU admission with invasive ventilatory support and/ or death for all causes, comparing four groups of patients: group 1 (G1): No treated (neither corticosteroid nor LMWH was administered); group 2 (G2): In which only methylpred-

*Corresponding author: Fabio Anastasio, MD, ASST Valtellina and Alto Lario, "Eugenio Morelli Hospital", Sondalo (SO), Italy, Via Zubiani 33, 23035 Sondalo (SO), Italy

Accepted: April 28, 2021

Published online: April 30, 2021

Citation: Anastasio F, Scarnecchia E, Barbuto S, et al. (2021) Impact of Corticosteroids and Anticoagulant Combined Treatment on Patients Affected by COVID-19 Pneumonia. Res Rev Infect Dis 4(1):125-137 


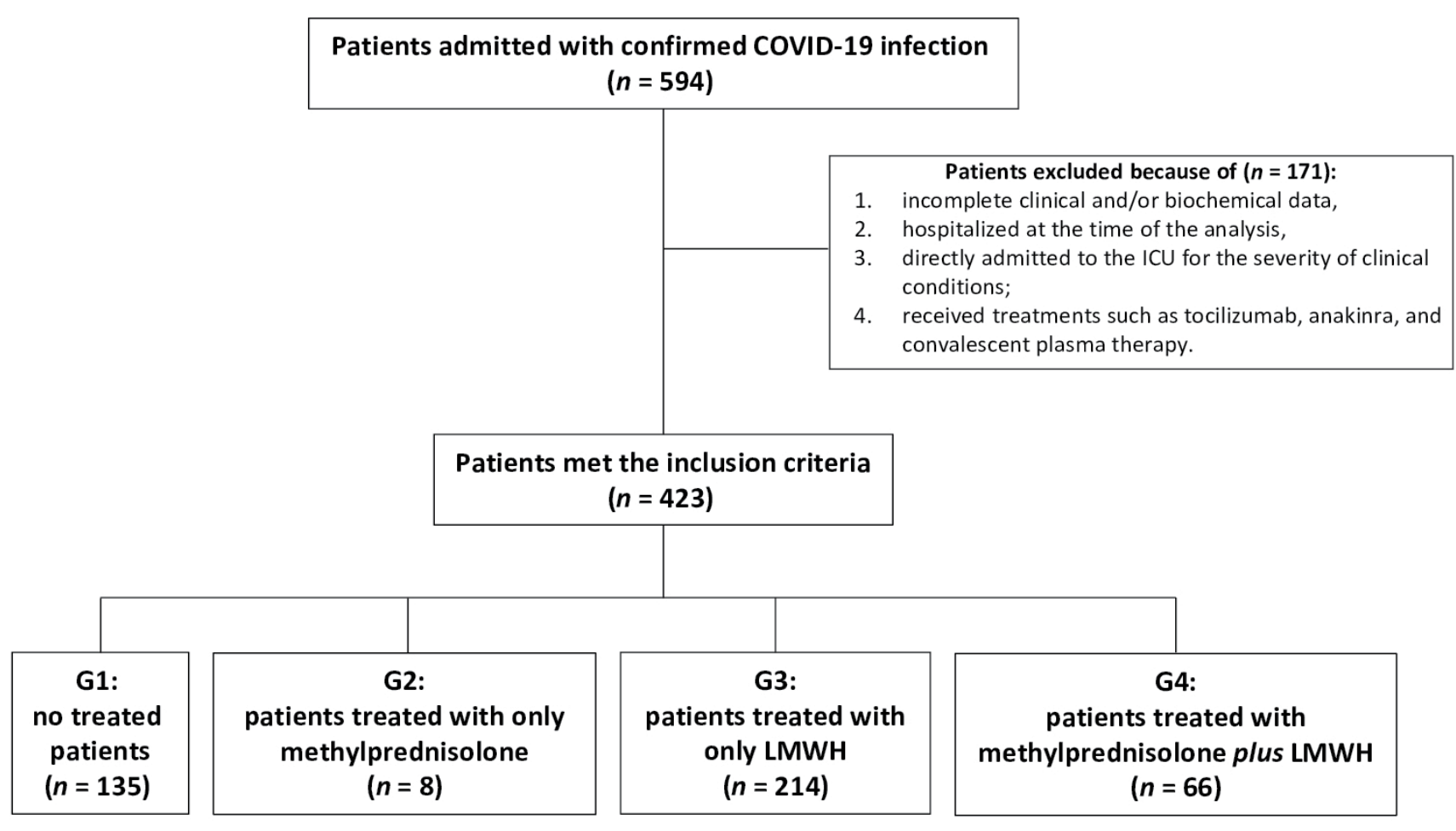

Figure 1: Flow-chart of the study.

Abbreviations: ICU: Intensive care unit; LMWH: Low-molecular-weight heparin.

nisolone was administered; group 3 (G3): Including patients who received only LMWH treatment; group 4 (G4): Patients treated with combined methylprednisolone plus LMWH.

\section{Statistical analysis}

Continuous variables were expressed as median and interquartile range (IQR) when not-normally distributed; categorical variables were presented as absolute value and percentage. Differences between groups were assessed by median test and Kruskal-Wallis test applying pairwise comparison and Bonferroni correction. Chi-square statistics were used to assess differences between categorical variables. The multicollinearity was examined using KMO and Bartlett's Test and the variance inflation factor (VIF): Variables with VIF > 3 were excluded by the same multivariable model. All baseline significant variables $(p<0.05)$ were included in adjusted multivariate Cox regression model with time-dependent covariates. Results were reported as hazard ratios (HR) with associated 95\% confidence intervals $(\mathrm{Cl})$.

Statistical analysis was performed with SPSS software version 26.0 (Statistical Package for Social Sciences, software; SPSS Inc, Chicago, Illinois, USA), and a $p$-value of 0.05 or less was considered statistically significant.

\section{Results}

\section{Characteristics of patients}

594 consecutive patients with confirmed COVID-19 infection were hospitalized in COVID-19 Department. Of those, 171 were excluded from the analysis because did not meet the inclusion criteria. In more detail, we excluded patients with in- complete clinical and/or biochemical information, those who were still hospitalized at the time of the analysis, and those who were directly admitted to the ICU for the severity of clinical conditions. Lastly, we excluded also patients who received treatments such as to cilizumab or anakinra (Figure 1).

Table 1, Table 2 and Supplemental Table 1 (see Supplemental Appendix) include the baseline data from a total of 423 analyzed patients and the same characteristics divided for each subgroup 276 (65.2\%) were males and 147 (34.8\%) females; the median (IQR) age was 71 (59-80). The distribution of age classes divided for sex is represented in the Supplemental Appendix-Supplemental Figure 1. The median body mass index (BMI) was $26.4\left(23.9-30.3 \mathrm{~kg} / \mathrm{m}^{2}\right) ; 73(17.3 \%)$ patients were obese $\left(\mathrm{BMI}>30 \mathrm{~kg} / \mathrm{m}^{2}[33,34]\right)$. The Charlson index showed a median score of 4 (2-6) and the median SOFA score was 1 (1-2). At the time of the hospitalization, $87 \%$ of patients needed oxygen support with $\mathrm{SpO}_{2} / \mathrm{FiO}_{2}$ ratio ranging > 300 in $36 \%$ of patients, between 220 and 300 in $21 \%$, between 140 and 220 in 13\%, and < 140 in $17 \%$ of cases. The median of $\mathrm{SpO}_{2} / \mathrm{FiO}_{2}$ ratio was 296 (175-442). Particular focus was given to the climax point of lung failure corresponding to the worst clinical respiratory condition from the admission, based on the worst $\mathrm{SpO}_{2} / \mathrm{FiO}_{2}$ ratio. A median of 2 (1-5) days was registered between the hospitalization and the detection of the lowest $\mathrm{SpO}_{2} / \mathrm{FiO}_{2}$ ratio.

135 patients did not receive any therapy (G1), 8 patients received only methylprednisolone (G2), 214 patients received LMWH (G3), and 66 patients received LMWH plus methylprednisolone (G4). Table 1 and Table 2 show the differences between groups. The $\mathrm{SpO}_{2} / \mathrm{FiO}_{2}$ ratio at the admission was 
Citation: Anastasio F, Scarnecchia E, Barbuto S, et al. (2021) Impact of Corticosteroids and Anticoagulant Combined Treatment on Patients Affected by COVID-19 Pneumonia. Res Rev Infect Dis 4(1):125-137

Table 1: Baseline characteristics of patients affected by COVID-19 pneumonia divided by type of received treatment.

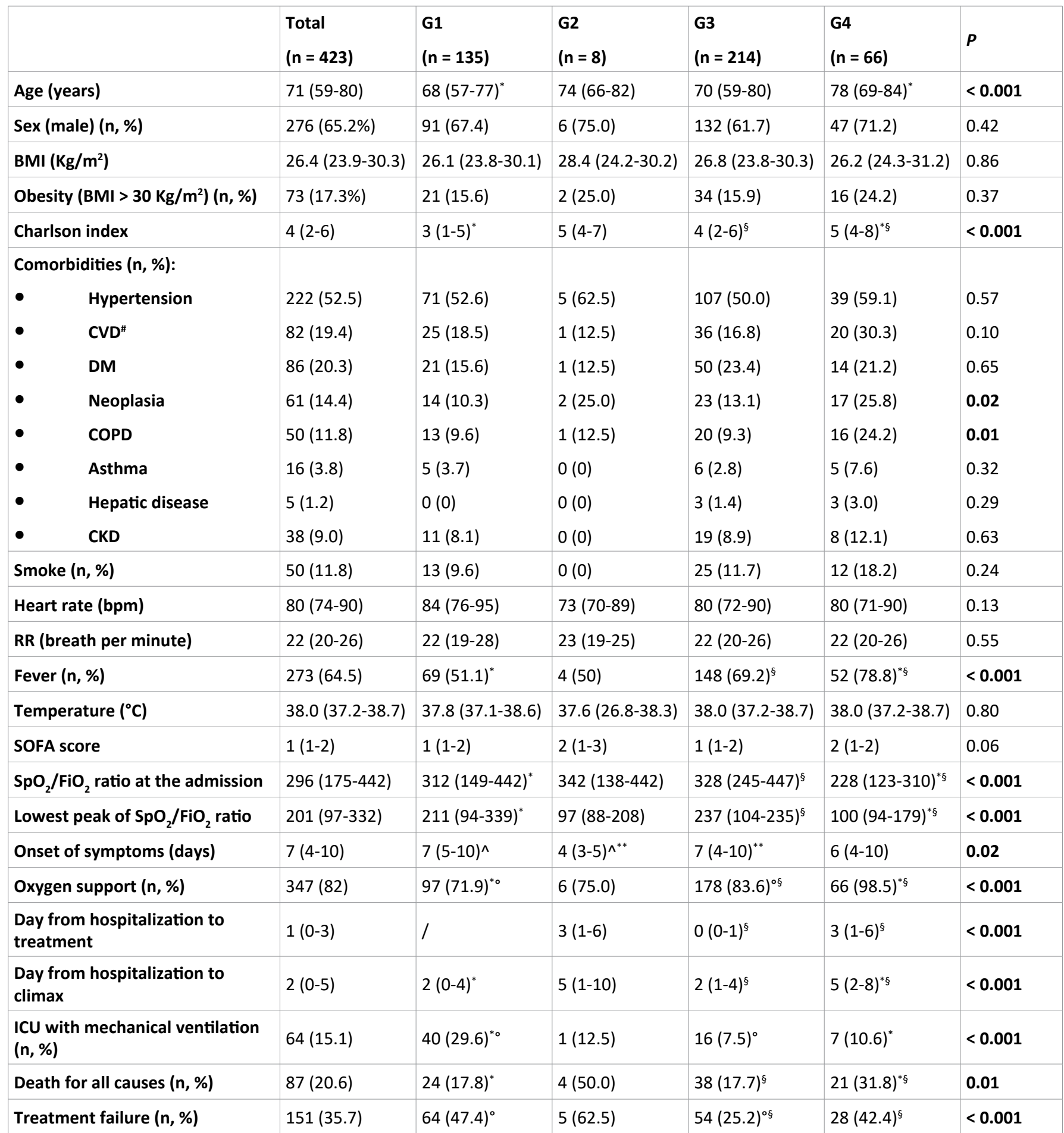

Data are expressed as median \pm interquartile range (IQR) when not specified.

"CVD included acute coronary syndrome, chronic heart failure, arrhythmias.

*Significant difference between G1 and G4; §Significant difference between G3 and G4; ^Significant difference between G1 and G2; ${ }^{* *}$ Significant difference between $\mathrm{G} 2$ and G3; ${ }^{\circ}$ Significant difference between $\mathrm{G} 1$ and $\mathrm{G} 3$

Abbreviations: BMI: Body mass index; CVD: Cardiovascular disease; DM: Diabetes mellitus; COPD: Chronic obstructive pulmonary disease; CKD: Chronic kidney disease; RR: Respiratory rate; SOFA: Sequential organ failure assessment; $\mathrm{SpO}_{2} / \mathrm{FiO}_{2}$ : Oxygen saturation to fraction of inspired oxygen ratio; ICU: Intensive care unit.

worse in $\mathrm{G} 4$ patients $(p<0.001)$ and the rate of oxygen support was significantly higher in patients of G4 (compared to all other groups, $p$ 0.001).
The international statements in the first months of the pandemic advised against the use of corticosteroids in the COVID-19 pneumonia patient's management [35-37]. For this reason, corticosteroids were not administered during 
Citation: Anastasio F, Scarnecchia E, Barbuto S, et al. (2021) Impact of Corticosteroids and Anticoagulant Combined Treatment on Patients Affected by COVID-19 Pneumonia. Res Rev Infect Dis 4(1):125-137

Table 2: Main biochemical data of patients affected by COVID-19 pneumonia divided by type of received treatment.

\begin{tabular}{|c|c|c|c|c|c|c|}
\hline$N / L$ & $5.6(3.5-9.6)$ & $6.3(3.5-10.4)$ & $7.8(2.6-24.7)$ & $4.9(3.3-9.0)$ & $6.4(3.9-11.6)$ & 0.11 \\
\hline Platelets $(1000 / \mu \mathrm{l})$ & $206(152-275)$ & $192(148-259)$ & $222(143-248)$ & $211(161-292)$ & $210(141-269)$ & 0.19 \\
\hline aPTT (sec) & $1.0(0.9-1.1)$ & $1.0(0.9-1.1)$ & $1.0(0.9-1.0)$ & $1.0(0.9-1.1)$ & $1.0(0.9-1.1)$ & 0.71 \\
\hline INR & $1.4(1.2-2.6)$ & $1.5(1.3-2.8)$ & / & $1.3(1.2-2.5)$ & $1.3(1.2-4.6)$ & 0.79 \\
\hline D-dimer (ng/ml) & $1081(620-2102)$ & $1245(736-2411)$ & $1142(658-3089)$ & $986(536-2098)$ & $1174(749-2026)$ & 0.25 \\
\hline HS troponin I ( $\mu \mathrm{g} / \mathrm{I})$ & $12.8(4.8-37.7)$ & $24.7(5.1-56.0)^{\circ}$ & $4.0(3.0-8.7)$ & $8.0(3.2-23.4)^{\S^{\circ}}$ & $23.7(12.1-47.9)^{\S}$ & $<0.001$ \\
\hline BNP (pg/ml) & $76(31-180)$ & $67(13-195)$ & $53(31-68)$ & $74(30-157)$ & $132(44-227)$ & 0.46 \\
\hline РCT (ng/ml) & $0.14(0.07-0.45)$ & $0.18(0.06-0.81)$ & $0.31(0.07-1.82)$ & $0.12(0.06-0.29)^{\S}$ & $0.18(0.09-0.52)^{\S}$ & 0.008 \\
\hline CRP (mg/l) & 80.9 (31.5-144.2) & $91.7(35.4-145.8)$ & $102.7(36.7-191.8)$ & $72.9(24.5-130.4)^{\S}$ & $91.7(51.2-157.1)^{\S}$ & 0.05 \\
\hline Ferritin (ng/ml) & $811(368-1903)$ & $1704(629-3584)^{\circ}$ & / & $743(273-1450)^{\circ}$ & 793 (538-2624) & 0.04 \\
\hline Cholinesterase (U/L) & $\begin{array}{l}7741 \\
(6132-9367)\end{array}$ & $\begin{array}{l}8083 \\
(6718-9378)^{*}\end{array}$ & $\begin{array}{l}6851 \\
(5868-7731)\end{array}$ & $\begin{array}{l}7945 \\
(6211-9468)^{\S}\end{array}$ & $\begin{array}{l}6402 \\
(5534-8552)^{* \S}\end{array}$ & 0.01 \\
\hline Serum creatinine $(\mathrm{mg} / \mathrm{dl})$ & $0.9(0.8-1.3)$ & $1.0(0.7-1.3)$ & $1.1(0.9-1.8)$ & $0.9(0.8-1.2)$ & $1.0(0.7-1.4)$ & 0.37 \\
\hline Proteinuria (mg/l) & $300(150-1000)$ & $300(37-1000)$ & $650(300-2500)$ & $300(150-500) \S$ & $300(150-1000)^{\S}$ & 0.02 \\
\hline Total bilirubin (mg/dl) & $0.6(0.4-0.8)$ & $0.6(0.4-0.8)$ & $0.7(0.4-1.0)$ & $0.6(0.4-0.8)$ & $0.6(0.4-0.8)$ & 0.92 \\
\hline ALT (U/L) & $29(19-48)$ & $32(22-54)^{\circ}$ & $24(15-33)$ & $26(17-47)^{\circ}$ & $29(18-45)$ & 0.04 \\
\hline AST (U/L) & $36(27-57)$ & $40(29-62)$ & $45(41-53)$ & $34(25-51)$ & $40(30-57)$ & 0.02 \\
\hline Gamma-GT (U/L) & $51(27-93)$ & $60(29-120)$ & $40(22-58)$ & $43(25-85)$ & $54(36-84)$ & 0.05 \\
\hline LDH (U/L) & $320(242-417)$ & $333(245-487)$ & $385(267-503)$ & $298(228-397)^{\S}$ & $348(269-466)^{\S}$ & 0.01 \\
\hline
\end{tabular}

Data are expressed as median \pm interquartile range (IQR) when not specified.

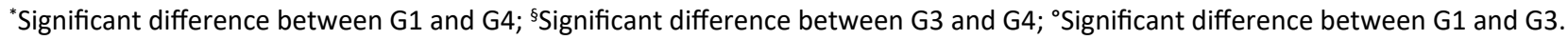

Abbreviations: N/L: Neutrophils/leucocytes ratio; aPTT: Activated partial thromboplastin time; INR: International normalized ratio; PCT: Procalcitonin; CRP: C-reactive protein; BNP: B-type natriuretic peptide; ALT: Alanine transferase; AST: Aspartate aminotransferase; LDH: Lactate dehydrogenase; gamma-GT: Gamma-glutamyltransferase.

the hospitalization, but only when the clinical and lung parameters were critical (i.e., $\mathrm{SpO}_{2} / \mathrm{FiO}_{2}$ ratio $<220$ - diagnosis of ARDS), causing differences in administration timing in our four groups. Therefore, treatment was started at different times for our four groups: A median of 3 (1-6) days after hospitalization in $\mathrm{G} 2$ and $\mathrm{G} 4$, and 0 (0-1) days in G3. Climax point of clinical status (i.e., the worst $\mathrm{SpO}_{2} / \mathrm{FiO}_{2}$ ratio) was registered after 2 (0-4) days in G1, 5 (1-10) days in G2, 2 (1-4) days in $\mathrm{G} 3$, and $5(2-8)$ days in $\mathrm{G} 4$.

\section{Study endpoint}

Ina total of 151 patients (35.7\%) the composite study endpoint (e.g., treatment failure defined as ICU admission and/or death for all-cause) has been observed. After a median of 2 (1-4) days of hospitalization, 64 patients were admitted to the ICU (15.1\%) and supported by invasive mechanical ventilation. All-cause of death were observed in 87 subjects $(20.5 \%)$.

Treatment failure was significantly lower for LMWH-treated (G3) compared to G1 ( $25.2 \%$ vs. $47.4 \%, p<0.001)$ and to G4 (25.2\% vs. $42.4 \%, p<0.001)$.

In more detail, the rate of patients admitted to the ICU and supported by invasive mechanical ventilation was higher in $\mathrm{G} 1$ compared to $\mathrm{G} 3(29.6 \%$ vs.7.5\%, $p<0.001)$ and compared to G4 (29.6\% vs. $10.6 \%, p=0.007)$. The rate of death for all causes was increased in patients who received only methylprednisolone $(\mathrm{G} 2)$ compared to $\mathrm{G} 1, \mathrm{G} 3$, and $\mathrm{G} 4(p=0.01)$.
Moreover, we also observed significantly increased rates of all-cause death between G1 and G4 (31.8\% vs. $17.8 \%, p=$ $0.02)$, and between $\mathrm{G} 3$ and $\mathrm{G} 4$ ( $31.8 \%$ vs. $17.7 \%, p=0.02)$.

The main characteristics of patients' ongoing treatment success or failure are shown in Supplemental Table 2 of Supplemental Appendix. As expected, the treatment success was reached by younger people, most of them were non-obese, females, with a significantly lower percentage of comorbidities such as hypertension, diabetes, smoking habit, and dementia. They showed also significantly lower Charlson index and SOFA scores. The $\mathrm{SpO}_{2} / \mathrm{FiO}_{2}$ ratio was higher in survived patients (340 [261-447] vs. 166 [166-305], p < 0.001) (Supplemental Table 2).

\section{Survival predictors}

The Cox regression analysis showed a significantly positive correlation between treatment failure and age (HR $4.90,95 \% \mathrm{Cl} 1.93-12.46, p=0.001)$, male sex (HR 2.13, 95\% Cl $1.45-3.12, p<0.001$ ), obesity (HR 1.69, 95\%Cl 1.16-2.46, $p$ $=0.006)$, SOFA score (HR 1.89, 95\% Cl 1.33-2.69, $p<0.001)$, and $\mathrm{SpO}_{2} / \mathrm{FiO}_{2}$ ratio $(\mathrm{HR} 0.35,95 \% \mathrm{Cl} 0.28-043, p<0.001$ ) (Table 3). Amongst the laboratory tests, in the multivariate analysis, treatment failure was statistically associated with a higher value of neutrophils/lymphocytes (N/L) ratio (HR 1.36, $95 \% \mathrm{Cl} 1.09-1.69, p=0.006)$, PCT (HR 1.23, 95\%Cl 1.07-1.41, $p=0.004), \mathrm{CRP}(\mathrm{HR} 1.28,95 \% \mathrm{Cl} 1.04-1.59, p=0.02), \mathrm{LDH}(\mathrm{HR}$ 
Citation: Anastasio F, Scarnecchia E, Barbuto S, et al. (2021) Impact of Corticosteroids and Anticoagulant Combined Treatment on Patients Affected by COVID-19 Pneumonia. Res Rev Infect Dis 4(1):125-137

Table 3: Univariate and multivariate analyses.

\begin{tabular}{|c|c|c|c|c|c|c|c|c|c|}
\hline \multirow[t]{2}{*}{ Covariates } & \multicolumn{3}{|c|}{ Univariate } & \multicolumn{3}{|c|}{ Multivariate model 1} & \multicolumn{3}{|c|}{ Multivariate model 2} \\
\hline & $P$ & HR & $95 \% \mathrm{Cl}$ & $P$ & HR & $95 \% \mathrm{Cl}$ & $P$ & $H R$ & $95 \% \mathrm{Cl}$ \\
\hline Log Age & 0.003 & 3.76 & $1.55-9.10$ & 0.001 & $4.90^{*}$ & $1.93-12.46$ & 0.04 & $3.34^{*}$ & $1.07-10.4$ \\
\hline Sex Male & 0.001 & 1.91 & $1.31-2.78$ & $<0.001$ & $2.13^{*}$ & $1.45-3.12$ & 0.05 & $1.54^{*}$ & $1.00-2.38$ \\
\hline Obesity & 0.01 & 1.61 & $1.10-2.34$ & 0.006 & $1.69^{*}$ & $1.16-2.46$ & 0.002 & $1.88^{*}$ & $1.25-2.83$ \\
\hline Charlson index & 0.003 & 1.08 & $1.03-1.14$ & 0.44 & & & / & & \\
\hline Number of comorbidities & 0.002 & 1.12 & $1.04-1.21$ & 0.23 & & & / & & \\
\hline Any comorbidity & 0.02 & 1.81 & $1.12-2.93$ & 0.47 & & & / & & \\
\hline Connective disease & 0.05 & 2.15 & $1.01-4.60$ & 0.57 & & & / & & \\
\hline Hypertension & 0.03 & 1.43 & $1.03-1.98$ & 0.85 & & & / & & \\
\hline Log SOFA score & $<0.001$ & 1.72 & $1.28-2.31$ & 0.009 & 1.52 & $1.11-2.08$ & $<0.001$ & $1.89^{*}$ & $1.33-2.69$ \\
\hline Log initial $\mathrm{SpO}_{2} / \mathrm{FiO}_{2}$ ratio & $<0.001$ & 0.32 & $0.26-0.39$ & $<0.001$ & 0.36 & $0.29-0.44$ & $<0.001$ & $0.35^{*}$ & $0.28-0.43$ \\
\hline $\log N / L$ ratio & $<0.001$ & 1.99 & $1.63-2.45$ & $<0.001$ & 1.85 & $1.51-2.28$ & 0.006 & 1.36 & $1.09-1.69$ \\
\hline Log D-dimer & $<0.001$ & 1.43 & $1.25-1.63$ & $<0.001$ & 1.42 & $1.23-1.64$ & 0.74 & & \\
\hline Log PCT & $<0.001$ & 1.51 & $1.37-1.66$ & $<0.001$ & 1.46 & $1.32-1.62$ & 0.004 & 1.23 & 1.07-1.41 \\
\hline Log CRP & $<0.001$ & 1.78 & $1.48-2.16$ & $<0.001$ & 1.67 & $1.37-2.02$ & 0.02 & 1.28 & $1.04-1.59$ \\
\hline Log Ferritin & 0.001 & 1.56 & $1.20-2.01$ & 0.005 & 1.52 & $1.14-2.03$ & 0.26 & & \\
\hline Log HS troponin I & $<0.001$ & 1.25 & $1.14-1.36$ & $<0.001$ & 1.25 & $1.13-1.39$ & 0.03 & 1.13 & 1.01-1.27 \\
\hline Log Proteinuria & $<0.001$ & 1.77 & $1.32-2.37$ & $<0.001$ & 1.75 & $1.29-2.37$ & 0.004 & 1.62 & $1.17-2.24$ \\
\hline Log Creatinine & 0.03 & 1.35 & $1.02-1.77$ & 0.44 & & & / & & \\
\hline Log LDH & $<0.001$ & 3.85 & $2.77-5.34$ & $<0.001$ & 3.56 & $2.52-5.01$ & $<0.001$ & 2.31 & $1.54-3.46$ \\
\hline Log Albumin & 0.02 & 0.31 & $0.12-0.82$ & 0.06 & 0.38 & $0.14-1.05$ & 0.44 & & \\
\hline
\end{tabular}

Not-normal distributed variables were transformed into a logarithmic scale.

Multivariate Model 1: Cox proportional-hazard model adjusted for: age, sex and obesity.

Multivariate Model 2: Cox proportional-hazard model adjusted for: age, sex, obesity, $\mathrm{SpO}_{2} / \mathrm{FiO}_{2}$ ratio and SOFA score.

Abbreviations: N/L: Neutrophils/leucocytes ratio; PCT: Procalcitonin; CRP: C-reactive protein; LDH: Lactate dehydrogenase; $\mathrm{SpO}_{2} / \mathrm{FiO}_{2}$ : Oxygen saturation to fraction of inspired oxygen ratio; SOFA: Sequential organ failure assessment.

2.31, 95\% Cl 1.54-3.46, $p<0.001)$, HS troponin I (HR 1.13, $95 \% \mathrm{Cl} 1.01-1.27, p=0.03)$, and proteinuria (HR 1.62, $95 \% \mathrm{Cl}$ 1.17-2.24, $p=0.004$ ) (Table 3).

\section{Effect of treatment}

At the univariate analysis, the LMWH (HR $0.61,95 \% \mathrm{Cl}$ 0.41-0.89, $p=0.01$ ), but not methylprednisolone treatment ( $p=0.32$ ), exhibited a significant negative correlation with treatment failure. The different timing of methylprednisolone administration, related to the climax point of clinical and radiological conditions, was included in the analysis, showing an inverse significant correlation between methylprednisolone administration and treatment failure ( $\mathrm{HR} 0.48,95 \% \mathrm{Cl} 0.30$ $0.75, p=0.001$ ). Response to treatment was then corrected, in a multivariate analysis, for significant prognostic variables, for clinical conditions at the hospitalization (i.e., age, sex, BMI, SOFA score, and $\mathrm{SpO}_{2} / \mathrm{FiO}_{2}$ ratio), and for the different clinical conditions at the time of methylprednisolone administration (i.e., worst $\mathrm{SpO}_{2} / \mathrm{FiO}_{2}$ ratio). Both of $\mathrm{LMWH}$ (HR 0.51, $95 \% \mathrm{Cl}$ 0.33-0.77 $p=0.001$ ) and methylprednisolone treatments (HR $0.53,95 \% \mathrm{Cl} 0.33-0.84, p=0.007$ ) showed a significant prognostic value.
According to the hypothesis of our study, that is the combined effect of LWMH plus corticosteroids could reduce the severity of COVID-19 pneumonia, analyzing the different therapeutic strategies between the four groups, we observed that G4 (LMWH plus methylprednisolone) showed the best prognosis compared to non-treated group (G1) (HR 0.47, $95 \% \mathrm{Cl} 0.27-0.82, p=0.007)$. G3 showed an increased prognosis compared to $\mathrm{G} 1$ (HR $0.59,95 \% \mathrm{Cl} 0.36-0.95, p=0.03$ ). G2 didn't show improvement ( $p=0.92$ ) (see Supplemental Table 3 of Supplemental Appendix). Additionally, we observed a better prognosis for $\mathrm{G} 4$ patients vs. G3 (HR 0.59, 95\% Cl 0.35$0.97, p=0.04$ ), especially versus $\mathrm{G} 1+\mathrm{G} 2+\mathrm{G} 3$ (HR $0.44,95 \% \mathrm{Cl}$ $0.28-0.71, p<0.001$ ). Differences between $\mathrm{G} 2$ and $\mathrm{G} 3$ or $\mathrm{G} 4$ were not significant due to the small sample size of $G 2$.

The cumulative risk of treatment failure after multivariate analysis in the four groups is showed in Figure 2 and the cumulative risk of G4 vs. G1 + G2 + G3 in Figure 3.

Furthermore, after stratifying patients in four groups according to the $\mathrm{SpO}_{2} / \mathrm{FiO}_{2}$ ratio thresholds (i.e., a) 300-400; b) $220-300$; c) $140-200$; d) < 140), we found a significant effect of combined LMWH plus methylprednisolone administration on treatment failure in patients with $\mathrm{SpO}_{2} / \mathrm{FiO}_{2}$ ratio between 


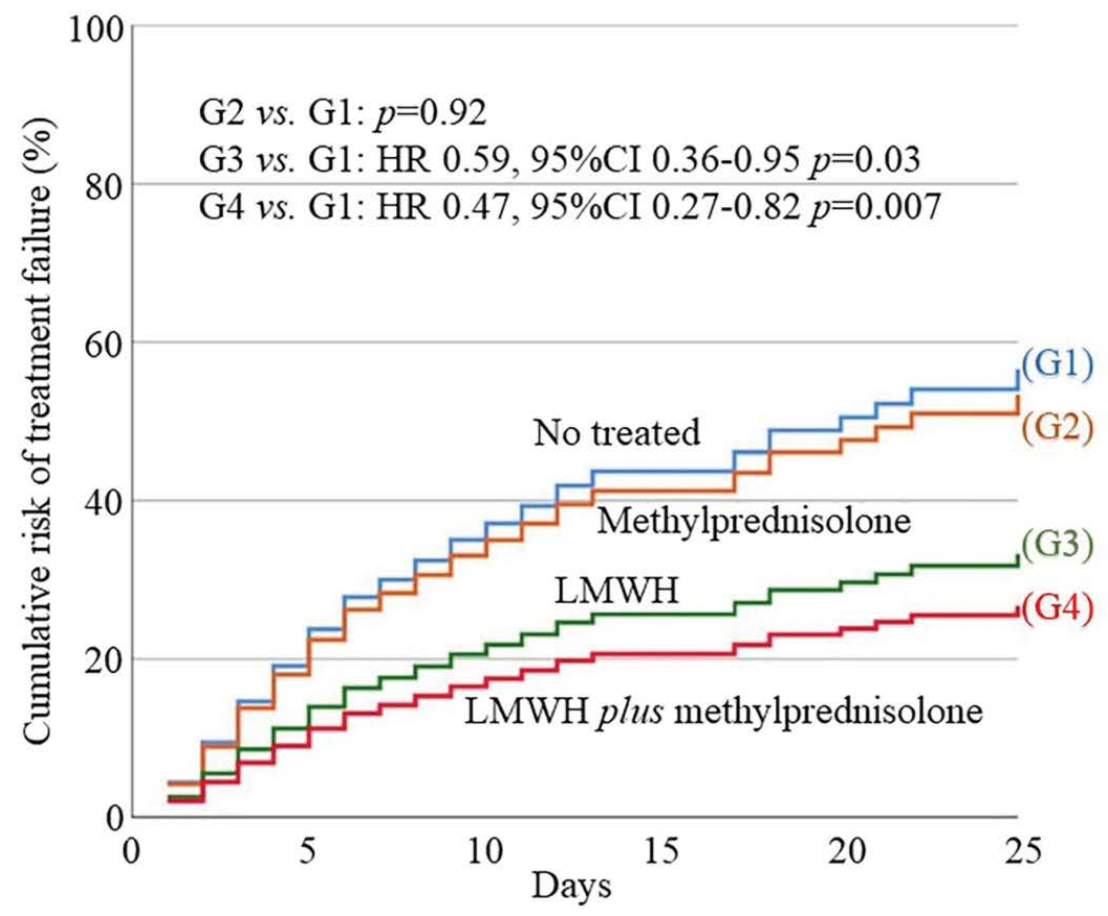

Figure 2: Cumulative risk (\%) of treatment failure according to the treatment strategies (group $1(\mathrm{G} 1, \mathrm{n}=135)$ : Non-treated patients; group $2(G 2, n=8)$ : Patients treated by methylprednisolone; group $3(G 3, n=241)$ : Subjects receiving low-molecular-weight heparin $(\mathrm{LMWH})$; group $4(\mathrm{G} 4, \mathrm{n}=66)$ : Patients treated with combined therapy LMWH plus methylprednisolone) for a median follow-up of 10 days.

Abbreviations: LMWH, low-molecular-weight heparin.

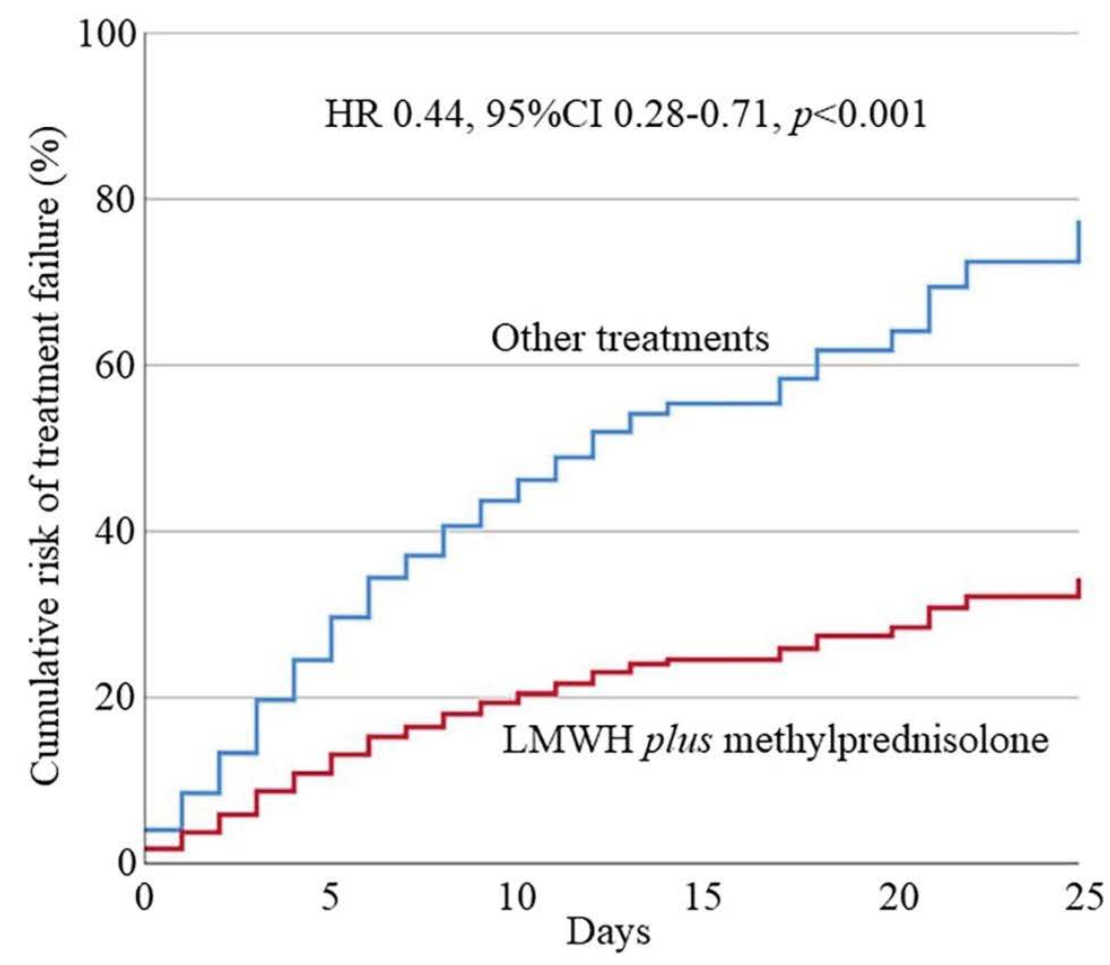

Figure 3: Cumulative risk (\%) of treatment failure comparing the subgroup G4 (patients treated with combined therapy LMWH plus methylprednisolone) compared to all other therapeutic strategies for a median follow-up of 10 days.

Abbreviations: LMWH: Low-molecular-weight heparin; HR: Hazard ratio; CI: Confidence interval. 
Citation: Anastasio F, Scarnecchia E, Barbuto S, et al. (2021) Impact of Corticosteroids and Anticoagulant Combined Treatment on Patients Affected by COVID-19 Pneumonia. Res Rev Infect Dis 4(1):125-137

$140-220$ (HR 0.25, 95\% Cl 0.07-0.87, $p=0.03)$ and in those with $<140$ (HR 0.49, 95\% Cl 0.27-0.91, $p=0.02$ ) (see Supplemental Table 4 of Supplemental Appendix), suggesting a better effect of this combined treatment in those cases with worse respiratory conditions in terms of gas exchange.

\section{Discussion}

By our knowledge, this study documented, for the first time, that in patients affected by COVID-19 pneumonia combined therapy with LMWH plus methylprednisolone is associated with a better outcome with a significant reduction of all-cause death rate and/or ICU admission needing of invasive mechanical ventilation.

SARS-CoV-2 infection is dominated by an acute, often bilateral, pneumonic involvement characterized by diffuse alveolar damage with inflammatory infiltrates and microvascular thrombosis, configuring an ARDS $[6,7,38]$. The subsequent MOF would appear secondary to the massive host immune response and the inflammatory organs injury. Hence, based on this hyperinflammation state caused by an increase in proinflammatory cytokines, such as IL-1 $\beta, \mathrm{IL}-6, \mathrm{IL}-8$, and TNF- $\alpha$, triggered by SARS-CoV- 2 infection, different studies have been performed with the aim to test the efficacy of IL-6 receptor blockade (e.g., tocilizumab) in hospitalized patients with COVID-19 pneumonia, but the results are still contradictory [39-41], just as the findings on the administration of convalescent plasma $[42,43]$. Moreover, convalescent plasma contains procoagulant factors, thus, administering it to patients with COVID-19 means introducing procoagulant factors into their bloodstream [44]. Recently, the IL-1 receptor antagonist, anakinra, was used to treat patients affected by severe COVID-19 disease forms with significantly reduced both need for invasive mechanical ventilation in the ICU and mortality and without serious side-effects [45]. However, beyond the efficacy and safety of these very expensive therapeutic strategies, which has yet to be definitively tested, their use is off-label and not always available, particularly in small peripheral care centers and hospitals.

On the other hand, numerous studies have been published evaluating the individual effectiveness of corticosteroid therapy [23-25]. Amongst these, the RECOVERY trial [46] was one of the most robust analysis demonstrating a moderate but significant reduction in mortality with corticosteroids administration (dexamethasone, $6 \mathrm{mg}$ per day). More recently, pooled data from seven randomized clinical trials, including the RECOVERY trial [46], were analysed in a meta-analysis promoted by WHO [25] and reported an improvement prognosis related to the administration of corticosteroids in critically ill COVID-19 patients with significant reduction in the mortality rate. Nevertheless, results of this meta-analysis are still challenged [38] because of, when data from the RECOVERY trial [46] were excluded from the analysis, this positive effect disappeared suggesting an overweight of this trial. Other studies showed contrasting results; in the CAPE COVID [23] no benefit of corticosteroids was found, as well as in the CoDEX trial [30], where corticosteroids significantly increased ventilator-free days during the first 28 days, but there was no benefit on 28-day mortality or length of stay in ICU in the
Metcovid study [47]. Conversely, the REMAP trial [48], which included 903 treated patients, hydrocortisone $(40 \mathrm{mg}$ intravenous every $6 \mathrm{~h}$ ) significantly reduced mortality from severe COVID-19.

Different analyses concerning the role of anticoagulant therapy in patients with COVID-19 disease have been published as well $[10,14,18-21,49,50]$. The rationale of anticoagulant administration, such as the LMWH, in COVID-19 disease is justified by the need to control the hypercoagulable state that has been proved in this patients and could be characterized by a wide clinical manifestation, form a local thrombosis in the pulmonary vasculature to pulmonary embolism, and vascular thromboembolism (VTE), until the onset of severe disseminated intravascular coagulation and thrombotic microangiopathy [4,51-55]. However, to date, only retrospective studies analyzed the effect of LMWH therapy on the survival rate in COVID-19 patients, most of them strongly suggested that anticoagulant therapy improves the prognosis of SARS-CoV-2 infection [10,14,18-20]. In the study by Tang and colleagues [14], the LMWH treatment appeared to be associated with a better prognosis in severe COVID-19 infection with sepsis-induced coagulopathy, reducing 28-day mortality rate. On the contrary, these results have not been confirmed in patients without coagulopathy [14].

Accordingly, both of these treatments seem to show a positive effect on the prognosis of COVID-19 patients, especially in the severe form of the disease with lungs involvement but, at present, no studies are available on the effectiveness of the LMWH associated with corticosteroids in the management of SARS-CoV-2 infection, compared to the single treatment administration. Simultaneous combined treatment with corticosteroid plus anticoagulant is under evaluation in only one trial [28].

In our retrospective observational study, conducted on COVID-19 pneumonia patients from the North of Italy, we reported a treatment failure (e.g., ICU admission and/or death for all-cause) in $35.7 \%$ of cases; after a median of 2 (1-4) days of hospitalization, 64 patients were admitted to the ICU for development of severe respiratory failure/ARDS (15.1\%). All patients in ICU were supported by invasive mechanical ventilation. The death for all-cause were observed in 87 (20.5\%) of subjects. Older age, male sex, obesity, a worse $\mathrm{SpO}_{2} / \mathrm{FiO}_{2}$ ratio at the admission, and higher SOFA score, showed a significant negative impact on outcome of COVID-19 patients, as previously highlighted in the literature [1]. However, unlike for what has been described, in our sample of subjects arterial hypertension and diabetes mellitus were not associated with a higher mortality risk $[1,56]$. Our findings show first that the combined therapy with prophylactic dose of LMWH plus i.v. administration of a weight-based dose of methylprednisolone significantly reduced the rate of treatment failure. This effect seems to be more significant for the G4 group (LMWH plus methylprednisolone) compared to non-treated patients (G1) (HR 0.47, 95\% Cl 0.27-0.82, $p=0.007$ ) and to patients with single LWMH therapy (G3) (HR 0.59, 95\% Cl 0.35-0.97, $p=$ 0.04). Furthermore, the significant effect of combined LMWH plus methylprednisolone administration (G4) on treatment failure appears to be more consistently in patients with $\mathrm{SpO}_{2} /$ 
Citation: Anastasio F, Scarnecchia E, Barbuto S, et al. (2021) Impact of Corticosteroids and Anticoagulant Combined Treatment on Patients Affected by COVID-19 Pneumonia. Res Rev Infect Dis 4(1):125-137

$\mathrm{FiO}_{2}$ ratio from 140 to 220 ( $\mathrm{HR} 0.25,95 \% \mathrm{Cl} 0.07-0.87, p=$ 0.03 ) and in those with < 140 (HR 0.49, 95\% Cl 0.27-0.91, $p=$ 0.02 ), corresponding approximately to a $\mathrm{FiO}_{2}$ needing oxygen support $>40 \%$. Patients with slight pulmonary involvement may not have a truly evident improvement in prognosis, in line with the current knowledge $[16,46]$.

The strength of our results, which suggest the effectiveness of combined LMWH plus corticosteroid therapy in a cohort of COVID-19 pneumonia patients, mostly in severe respiratory failure cases, was evident after adjustment for confounding factors. In addition, the solidity of our results lies the inclusion in the analysis of all demographic and anthropometric variables, and a complete laboratory assessment, for each patient enrolled from the start to the end of the study.

Nevertheless, our study has some limitations that must be pointed out. First, due to the retrospective design of the analysis, the study can only report associations, cannot investigate causality, and is susceptible to multiple sources of bias such as indication bias and hidden confounders. Second, the small sample size of each of the four therapy-based groups reduces the power of our findings; for example, the analysis on the $\mathrm{G} 2$ group, receiving methylprednisolone without LMWH, was not relevant, due to the sample exiguity (only 8 cases). Our analysis, indeed, concerns information on the first cases of COVID-19 pneumonia with rapid worsening, which has been collected retrospectively. Likely, for these cases, there was not yet sufficient evidence on the procoagulant state and the possible increased risk of thromboembolic complications of COVID-19 diseases, and on the use of LMWH as a critical therapeutic strategy [10]. Lastly, the time to methylprednisolone administration was delayed due to the lack of recommendations of corticosteroids treatment in the first weeks of the COVID-19 pandemic. However, we performed a statistical analysis able to reduce bias due to administration of therapy in patients after clinical improvement and we demonstrated a significant reduction in cumulative risk in the subgroup of LMWH plus methylprednisolone compared to other treatment strategies.

\section{Conclusion}

In conclusion, this retrospective observational cohort study shows that combined treatment with LMWH plus methylprednisolone during hospitalization was associated with a lower treatment failure rate in COVID-19 pneumonia patients. The effect appeared to be more relevant in patients with $\mathrm{SpO}_{2} / \mathrm{FiO}_{2}$ ratio $\leq 220$ and in those suffering from a more severe form of lung failure. These findings need to be confirmed by further double-blind randomized and with greater sample-sized clinical trials.

\section{Acknowledgements}

\section{Author contributions}

$F A, E S, S B$ and FS contributed to the acquisition of data. $F A, V B$ and GP contributed to analysis and interpretation of data for the work.

All authors contributed to design of the work, revising it critically for important intellectual content, final approval of the version to be published, agreement to be accountable for all aspects of the work in ensuring that questions related to the accuracy or integrity of any part of the work are appropriately investigated and resolved.

\section{Funding}

This research did not receive any specific grant from any funding agency in the public, commercial, or non-profit sector.

\section{Prior presentations}

None.

\section{Declaration of interest}

The authors have no conflicts of interest to declare.

\section{References}

1. Huang C, Wang Y, Li X, et al. (2020) Clinical features of patients infected with 2019 novel coronavirus in Wuhan, China. Lancet 395: P497-P506.

2. Phelan AL, Katz R, Gostin LO (2020) The novel coronavirus originating in Wuhan, China: Challenges for global health governance. JAMA 323: 709-710.

3. WHO (2020) Coronavirus disease 2019 (COVID-19). Situat Report 32: 1-16.

4. Sardiña-González C, López-Reboiro ML, Suárez-Fuentetaja R, et al. (2020) COVID 19 comprehensive management in a regional hospital of Northwestern Spain. Gac Med Mex 156: 294-297.

5. Kumar M, Al Khodor S (2020) Pathophysiology and treatment strategies for COVID-19. J Transl Med 18: 353.

6. Dolhnikoff M, Duarte-Neto AN, de Almeida Monteiro RA, et al. (2020) Pathological evidence of pulmonary thrombotic phenomena in severe COVID-19. J Thromb Haemost 18: 1517-1519.

7. Carsana L, Sonzogni A, Nasr A, et al. (2020) Pulmonary post-mortem findings in a series of COVID-19 cases from northern Italy: A two-centre descriptive study. Lancet Infect Dis S1473-3099: 30434-30435.

8. Zeng F, Huang Y, Guo Y, et al. (2020) Association of inflammatory markers with the severity of COVID-19: A meta-analysis. Int J Infect Dis 96: 467-474.

9. Moore JB, June $\mathrm{CH}(2020)$ Cytokine release syndrome in severe COVID-19. Science 368: 473-474.

10. Carfora V, Spiniello G, Ricciolino R, et al. (2020) Anticoagulant treatment in COVID-19: A narrative review. J Thromb Thrombolysis.

11. Poissy J, Goutay J, Caplan M, et al. (2020) Pulmonary embolism in patients with COVID-19: Awareness of an increased prevalence. Circulation 142: 184-186.

12. Mondal R, Lahiri D, Deb S, et al. (2020) COVID-19: Are we dealing with a multisystem vasculopathy in disguise of a viral infection? J Thromb Thrombolysis 50: 567-579.

13. López Castro J (2020) COVID-19 and thrombosis: Beyond a casual association. Med Clínica (English Ed) 155: 44.

14. Tang N, Bai $H$, Chen X, et al. (2020) Anticoagulant treatment is associated with decreased mortality in severe coronavirus disease 2019 patients with coagulopathy. J Thromb Haemost 18: 1094-1099. 
Citation: Anastasio F, Scarnecchia E, Barbuto S, et al. (2021) Impact of Corticosteroids and Anticoagulant Combined Treatment on Patients Affected by COVID-19 Pneumonia. Res Rev Infect Dis 4(1):125-137

15. Cattaneo M, Bertinato EM, Birocchi S, et al. (2020) Pulmonary embolism or pulmonary thrombosis in COVID-19? Is the recommendation to use high-dose heparin for thromboprophylaxis justified? Thromb Haemost 120: 1230-1232.

16. Prandoni P, Cattelan AM, Carrozzi L, et al. (2020) The hazard of fondaparinux in non-critically ill patients with COVID-19: Retrospective controlled study versus enoxaparin. Thromb Res 196: 395-397.

17. Gozzo L, Viale P, Longo L, et al. (2020) The potential role of heparin in patients with COVID-19: Beyond the anticoagulant effect. A Review. Front Pharmacol 11: 1307.

18. Albani F, Sepe L, Fusina F, et al. (2020) Thromboprophylaxis with enoxaparin is associated with a lower death rate in patients hospitalized with SARS-CoV-2 infection. A cohort study. EClinicalMedicine 27: 100562.

19. Paranjpe I, Fuster V, Lala A, et al. (2020) Association of treatment dose anticoagulation with in-hospital survival among hospitalized patients with COVID-19. J Am Coll Cardiol 76: 122-124.

20. Ionescu F, Jaiyesimi I, Petrescu I, et al. (2020) Association of anticoagulation dose and survival in hospitalized COVID-19 patients: A retrospective propensity score-weighted analysis. Eur J Haematol 106: 165-174.

21. Desai A, Voza G, Paiardi S, et al. (2021) The role of anti-hypertensive treatment, comorbidities and early introduction of LMWH in the setting of COVID-19: A retrospective, observational study in Northern Italy. Int J Cardiol 324: 249-254.

22. Sterne JAC, Murthy S, Diaz JV, et al. (2020) Association between administration of systemic corticosteroids and mortality among critically ill patients with COVID-19: A meta-analysis. JAMA 324: 1330-1341.

23. Dequin PF, Heming N, Meziani F, et al. (2020) Effect of hydrocortisone on 21-day mortality or respiratory support among critically ill patients with COVID-19: A randomized clinical trial. JAMA 324: 1298-1306.

24. Ye Z, Wang Y, Colunga-Lozano LE, et al. (2020) Efficacy and safety of corticosteroids in COVID-19 based on evidence for COVID-19, other coronavirus infections, influenza, community-acquired pneumonia and acute respiratory distress syndrome: A systematic review and meta-analysis. CMAJ 192: E756-E767.

25. Yang Z, Liu J, Zhou Y, et al. (2020) The effect of corticosteroid treatment on patients with coronavirus infection: A systematic review and meta-analysis. J Infect 81: E13-E20.

26. Gamulescu MA, Schalke B, Schuierer G, et al. (2006) Optic neuritis with visual field defect-possible ibuprofen-related toxicity. Ann Pharmacother 40: 571-573.

27. Bartoletti M, Marconi L, Scudeller L, et al. (2021) Efficacy of corticosteroid treatment for hospitalized patients with severe COVID-19: A multicentre study. Clin Microbiol Infect 27: 105-111.

28. Busani S, Tosi M, Mighali P, et al. (2020) Multi-centre, three arm, randomized controlled trial on the use of methylprednisolone and unfractionated heparin in critically ill ventilated patients with pneumonia from SARS-CoV-2 infection: A structured summary of a study protocol for a randomised controlled trials. Trials 21: 724 .

29. Charlson ME, Pompei P, Ales KL, et al. (1987) A new method of classifying prognostic comorbidity in longitudinal studies: Development and validation. J Chronic Dis 40: 373-383.

30. Vincent JL, Moreno R, Takala J, et al. (1996) The SOFA (Sepsis-related Organ Failure Assessment) score to describe organ dysfunction/failure. Intensive Care Med 22: 707-710.
31. Rice TW, Wheeler AP, Bernard GR, et al. (2007) Comparison of the SpO2/FIO2 ratio and the $\mathrm{PaO} 2 / \mathrm{FIO} 2$ ratio in patients with acute lung injury or ARDS. Chest 132: 410-417.

32. Lu X, Jiang L, Chen T, et al. (2020) Continuously available ratio of $\mathrm{SpO} 2 / \mathrm{FiO} 2$ serves as a noninvasive prognostic marker for intensive care patients with COVID-19. Respir Res 21: 194.

33. Anderson DR, Morgano GP, Bennett C, et al. (2019) American Society of Hematology 2019 guidelines for management of venous thromboembolism: Prevention of venous thromboembolism in surgical hospitalized patients. Blood Adv 3: 3898-3944.

34. Weir CB, Jan A (2019) BMI classification percentile and cut off points. StatPearls.

35. Russell CD, Millar JE, Baillie JK (2020) Clinical evidence does not support corticosteroid treatment for 2019-nCoV lung injury. Lancet 395: 473-475.

36. WHO (2020) Clinical management of severe acute respiratory infection ('SARI)|" when COVID-19 disease is suspected: Interim guidance, 13 March 2020. World Health Organization, Geneva.

37. Lombardy Section Italian Society Infectious And Tropical Diseases (2020) Vademecum for the treatment of people with COVID-19. Edition 2.0. Le Infez Med 28: 143-152.

38. Carlet J, Payen D, Opal SM (2020) Steroids for sepsis and ARDS: This eternal controversy remains with COVID-19. Lancet 396: e61-e62.

39. Guaraldi G, Meschiari M, Cozzi-Lepri A, et al. (2020) Tocilizumab in patients with severe COVID-19: A retrospective cohort study. Lancet Rheumatol 2: e474-e484.

40. Campins L, Boixeda R, Perez-Cordon L, et al. (2020) Early tocilizumab treatment could improve survival among COVID-19 patients. Clin Exp Rheumatol 38: 578.

41. Stone JH, Frigault MJ, Serling-Boyd NJ, et al. (2020) Efficacy of tocilizumab in patients hospitalized with Covid-19. N Engl J Med 383: 2333-2344.

42. Joyner MJ, Bruno KA, Klassen SA, et al. (2020) Safety update: COVID-19 convalescent plasma in 20,000 hospitalized patients. Mayo Clin Proc 95: 1888-1897.

43. Simonovich VA, Burgos Pratx LD, Scibona P, et al. (2020) A Randomized Trial of Convalescent Plasma in Covid-19 Severe Pneumonia. N Engl J Med NEJMoa2031304.

44. Sanfilippo F, La Rosa V, Astuto M (2021) Micro-thrombosis, perfusion defects, and worsening oxygenation in COVID-19 patients: A word of caution on the use of convalescent plasma. Mayo Clin Proc 96: 259.

45. Huet T, Beaussier H, Voisin O, et al. (2020) Anakinra for severe forms of COVID-19: A cohort study. Lancet Rheumatol 2: e393-e400.

46. The RECOVERY Collaborative Group, Wei Shen Lim, Jonathan $\mathrm{R}$ Emberson, et al. (2020) Dexamethasone in hospitalized patients with Covid-19 - preliminary report. N Engl J Med 17: NEJMoa2021436.

47. Jeronimo CMP, Farias MEL, Val FFA, et al. (2020) Methylprednisolone as adjunctive therapy for patients hospitalized with coronavirus Disease 2019 (COVID-19; Metcovid): A randomized, double-blind, phase iib, placebo-controlled trial. Clin Infect Dis.

48. The Writing Committee for the REMAP-CAP Investigators (2020) Effect of hydrocortisone on mortality and organ support in patients with severe COVID-19: The REMAP-CAP COVID-19 corticosteroid domain randomized clinical trial. JAMA 324: 1317-1329. 
49. Thachil J (2020) The versatile heparin in COVID-19. J Thromb Haemost 18: 1020-1022.

50. Li T, Lu H, Zhang W (2020) Clinical observation and management of COVID-19 patients. Emerg Microbes Infect 9: 687-690.

51. Abou-Ismail MY, Diamond A, Kapoor S, et al. (2020) The hypercoagulable state in COVID-19: Incidence, pathophysiology, and management. Thromb Res 194: 101-115.

52. Van Doremalen N, Bushmaker T, Morris DH, et al. (2020) Aerosol and surface stability of SARS-CoV-2 as compared with SARSCoV-1. N Engl J Med 382: 1564-1567.
53. Zuo Y, Yalavarthi S, Shi H, et al. (2020) Neutrophil extracellular traps in COVID-19. JCI Insight 5: e138999.

54. Katneni UK, Alexaki A, Hunt RC, et al. (2020) Coagulopathy and thrombosis as a result of severe COVID-19 infection: A microvascular focus. Thromb Haemost 120: 1668-1679.

55. Komiyama M, Hasegawa K (2020) Anticoagulant therapy for patients with Coronavirus Disease 2019: urgent need for enhanced awareness. Eur Cardiol 15: e58.

56. Grasselli G, Zangrillo A, Zanella A, et al. (2020) Baseline characteristics and outcomes of 1591 patients infected with SARSCoV-2 admitted to ICUs of the Lombardy region, Italy. JAMA 323: 1574-1581. 
Citation: Anastasio F, Scarnecchia E, Barbuto S, et al. (2021) Impact of Corticosteroids and Anticoagulant Combined Treatment on Patients Affected by COVID-19 Pneumonia. Res Rev Infect Dis 4(1):125-137

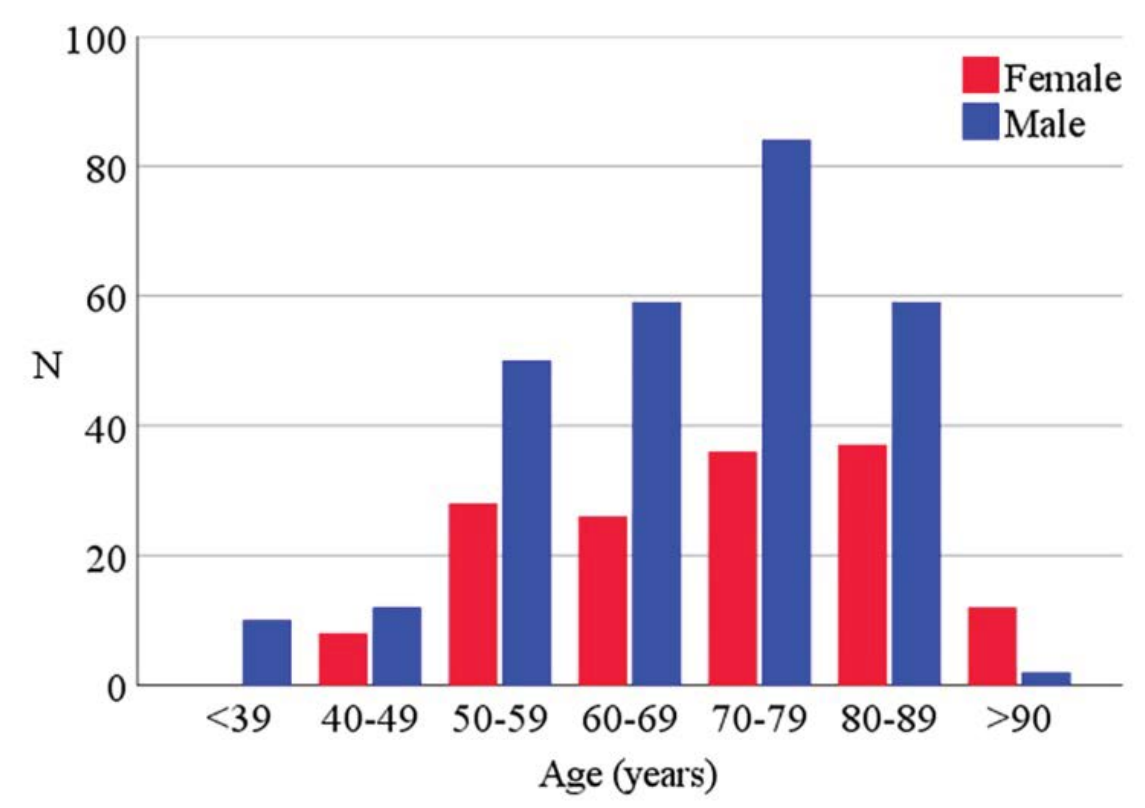

Supplemental Figure 1: Sex distribution for age-group.

Abbreviation: N: Number.

Supplemental Table 1: Main biochemical data of patients affected by COVID-19 pneumonia divided by type of received treatment.

\begin{tabular}{|l|l|l|l|l|l|l|}
\hline Neutrophils $\mathbf{( n / m ^ { 3 } )}$ & $4.9(3.4-6.7)$ & $4.9(3.4-7.0)$ & $4.2(2.3-8.9)$ & $4.8(3.3-6.2)$ & $5.1(3.8-7.9)$ & 0.33 \\
\hline Lymphocytes $\mathbf{( n / m ^ { 3 } )}$ & $0.8(0.6-1.2)$ & $0.8(0.6-1.1)$ & $0.6(0.2-0.9)$ & $0.9(0.6-1.2)$ & $0.7(0.5-1.2)$ & 0.11 \\
\hline Hemoglobin (g/dl) & $14.0(12.8-15.2)$ & $14.2(13.2-15.4)$ & $13.2(11.7-15.3)$ & $13.9(12.7-15.1)$ & $13.7(12.7-15.2)$ & 0.19 \\
\hline Albumin (g/l) & $25.7(22.3-29.7)$ & $25.3(21.7-29.7)$ & $/$ & $26.6(23.3-30.6)$ & $23.7(22.0-26.6)$ & 0.09 \\
\hline Creatine kinase (U/L) & $108(59-209)$ & $118(64-240)$ & $287(126-467)$ & $109(56-196)$ & $99(53-186)$ & 0.08 \\
\hline ALP (U/L) & $63(51-84)$ & $62(50-93)$ & $55(49-72)$ & $65(52-84)$ & $62(47-69)$ & 0.49 \\
\hline
\end{tabular}

Data are expressed as median \pm interquartile range (IQR) when not specified. Abbreviations: ALP: Alkaline phosphatase.

Supplemental Table 2: Baseline characteristics of patients affected by COVID-19 divided by treatment success or failure.

\begin{tabular}{|l|l|l|l|l|}
\hline & Total (423) & Treatment success (272) & Treatment failure (151) & $P$ \\
\hline Age, years & $71(59-80)$ & $69(56-79)$ & $74(66-82)$ & $<0.001$ \\
\hline Sex male (n,\%) & $276(65.2)$ & $161(59.2)$ & $115(76.2)$ & $<0.001$ \\
\hline Obesity (n,\%) & $73(17.3)$ & $37(13.6)$ & $36(23.8)$ & $\mathbf{0 . 0 0 8}$ \\
\hline Charlson index score & $4(2-6)$ & $3(2-5)$ & $4(3-7)$ & $<0.001$ \\
\hline SpO /FiO $_{\mathbf{2}}$ ratio & $296(175-442)$ & $340(261-447)$ & $166(166-305)$ & $<0.001$ \\
\hline SOFA score & $1(1-2)$ & $1(1-2)$ & $2(1-2)$ & $<0.001$ \\
\hline Hypertension (n,\%) & $222(52.5)$ & $130(47.8)$ & $92(60.9)$ & $\mathbf{0 . 0 0 9}$ \\
\hline Diabetes (n,\%) & $86(20.3)$ & $47(17.3)$ & $39(25.8)$ & $\mathbf{0 . 0 5}$ \\
\hline Smoking history (n,\%) & $50(11.8)$ & $26(9.6)$ & $24(15.9)$ & $\mathbf{0 . 0 5}$ \\
\hline Dementia (n,\%) & $53(12.5)$ & $26(9.6)$ & $27(17.9)$ & $\mathbf{0 . 0 1}$ \\
\hline
\end{tabular}

Data are expressed as median \pm interquartile range (IQR) when not specified.

Abbreviations: $\mathrm{SpO}_{2} / \mathrm{FiO}_{2}$ : Oxygen saturation to fraction of inspired oxygen ratio; SOFA: Sequential organ failure assessment. 
Citation: Anastasio F, Scarnecchia E, Barbuto S, et al. (2021) Impact of Corticosteroids and Anticoagulant Combined Treatment on Patients Affected by COVID-19 Pneumonia. Res Rev Infect Dis 4(1):125-137

Supplemental Table 3: Multivariate analysis between treatment strategies and treatment failure after correction for confounding factors (see the main text for additional explanations).

\begin{tabular}{|c|c|c|c|c|c|}
\hline & $\begin{array}{l}\text { G1 } \\
(n=135)\end{array}$ & $\begin{array}{l}\text { G2 } \\
(n=8)\end{array}$ & $\begin{array}{l}\text { G3 } \\
(n=214)\end{array}$ & $\begin{array}{l}\text { G4 } \\
(n=66)\end{array}$ & $P$ \\
\hline Treatment failure $(n, \%)$ & $64(47.4)^{*}$ & $5(62.5)$ & $54(25.2)^{* \S}$ & $28(42.4)^{\S}$ & $<0.001$ \\
\hline ICU with mechanical ventilation ( $n, \%)$ & $40(29.6)^{* \circ}$ & $1(12.5)$ & $16(7.5)^{*}$ & $7(10.6)^{\circ}$ & $<0.001$ \\
\hline Death for all causes (n, \%) & $24(17.8)^{\circ}$ & $4(50.0)$ & $38(17.7)^{\S}$ & $21(31.8)^{\circ \S}$ & 0.01 \\
\hline HR (vs. G1) & - & - & 0.59 & 0.47 & \\
\hline $95 \% \mathrm{Cl}$ (vs. G1) & - & - & $0.36-0.95$ & $0.27-0.82$ & \\
\hline$P$ (vs. G1) & - & 0.92 & 0.03 & 0.007 & \\
\hline \multicolumn{6}{|l|}{ HR (vs. G2) } \\
\hline \multicolumn{6}{|l|}{ 95\%Cl (vs. G2) } \\
\hline$P$ (vs. G2) & & & 0.92 & 0.15 & \\
\hline HR (vs. G3) & & & & 0.59 & \\
\hline 95\%Cl (vs. G3) & & & & $0.35-0.97$ & \\
\hline$P$ (vs. G3) & & & & 0.04 & \\
\hline
\end{tabular}

*Significant difference between G1 and G3; ${ }^{\circ}$ Significant difference between G1 and G4; ${ }^{\S}$ Significant difference between G3 and G4.

*Significant difference between $\mathrm{SpO}_{2} / \mathrm{FiO}_{2}$ ratio 300-400 and $\mathrm{SpO}_{2} / \mathrm{FiO}_{2}$ ratio < 140; ${ }^{\wedge}$ Significant difference between $\mathrm{SpO}_{2} / \mathrm{FiO}_{2}$ ratio $300-400$ and $\mathrm{SpO}_{2} / \mathrm{FiO}_{2}$ ratio 140-220; "Significant difference between $\mathrm{SpO}_{2} / \mathrm{FiO}_{2}$ ratio 220-300 and $\mathrm{SpO}_{2} / \mathrm{FiO}_{2}$ ratio 140-220; ${ }^{\circ}$ Significant difference between $\mathrm{SpO}_{2} / \mathrm{FiO}_{2}$ ratio $220-300$ and $\mathrm{SpO}_{2} / \mathrm{FiO}_{2}$ ratio < 140; ${ }^{\mathrm{S}}$ Significant difference between $\mathrm{SpO}_{2} / \mathrm{FiO}_{2}$ ratio $140-220$ and $\mathrm{SpO} / 2 / \mathrm{FiO}{ }_{2}$ ratio $<$ 140.

Supplemental Table 4: Multivariate analysis between $\mathrm{SpO}_{2} / \mathrm{FiO}_{2}$ ratio at baseline and combined therapy (LMWH plus methylprednisolone) versus no treatment.

\begin{tabular}{|c|c|c|c|c|c|}
\hline & $\begin{array}{l}\mathrm{SpO}_{2} / \mathrm{FiO}_{2} \text { ratio } 300-400 \\
(\mathrm{n}=197)\end{array}$ & $\begin{array}{l}\mathrm{SpO}_{2} / \mathrm{FiO}_{2} \text { ratio } 220-300 \\
(\mathrm{n}=88)\end{array}$ & $\begin{array}{l}\mathrm{SpO}_{2} / \mathrm{FiO}_{2} \text { ratio } 140-220 \\
(\mathrm{n}=69)\end{array}$ & $\begin{array}{l}\mathrm{SpO}_{2} / \mathrm{FiO}_{2} \text { ratio }<140 \\
(\mathrm{n}=69)\end{array}$ & $P$ \\
\hline $\begin{array}{l}\text { LMWH plus methyl } \\
\text { prednisolone }\end{array}$ & $17(8.6 \%)$ & $18(20.4 \%)$ & $15(21.7 \%)$ & $21(30.4 \%)$ & $<0.001$ \\
\hline Treatment failure & $35(17.8 \%)^{\wedge *}$ & $21(23.8 \%)^{\circ}$ & $31(44.9 \%)^{\wedge \S}$ & $55(79.7 \%)^{* \circ \S}$ & $<0.001$ \\
\hline ICU & $9(4.6 \%)^{\wedge *}$ & $6(6.8 \%)^{\circ \#}$ & $17(24.6 \%)^{\wedge \#}$ & $23(33.3 \%)^{* \circ}$ & $<0.001$ \\
\hline Death & $26(13.2 \%)^{*}$ & $15(17.0 \%)^{\circ}$ & $14(20.3 \%)^{\S}$ & $32(46.4 \%)^{* \circ \S}$ & $<0.001$ \\
\hline HR & 0.99 & 0.47 & 0.25 & 0.49 & \\
\hline $95 \% \mathrm{Cl}$ & $0.42-2.35$ & $0.14-1.55$ & $0.07-0.87$ & $0.27-0.91$ & \\
\hline$P$ & 0.98 & 0.21 & 0.03 & 0.02 & \\
\hline
\end{tabular}

*Significant difference between $\mathrm{SpO}_{2} / \mathrm{FiO}_{2}$ ratio 300-400 and $\mathrm{SpO}_{2} / \mathrm{FiO}_{2}$ ratio < 140; ${ }^{\circ}$ Significant difference between $\mathrm{SpO}_{2} / \mathrm{FiO}_{2}$ ratio $300-400$ and $\mathrm{SpO}_{2} / \mathrm{FiO}_{2}$ ratio 140-220; "Significant difference between $\mathrm{SpO}_{2} / \mathrm{FiO}_{2}$ ratio 220-300 and $\mathrm{SpO}_{2} / \mathrm{FiO}_{2}$ ratio 140-220; ${ }^{\circ}$ Significant difference between $\mathrm{SpO}_{2} / \mathrm{FiO}_{2}$ ratio 220-300 and $\mathrm{SpO}_{2} / \mathrm{FiO}_{2}$ ratio $<140$; ${ }^{5}$ Significant difference between $\mathrm{SpO}_{2} / \mathrm{FiO}_{2}$ ratio $140-220$ and $\mathrm{SpO}_{2} / \mathrm{FiO}_{2}$ ratio $<140$.

DOI: $10.36959 / 719 / 579$

Copyright: (c) 2021 Anastasio F, et al. This is an open-access article distributed under the terms of the Creative Commons Attribution License, which permits unrestricted use, distribution, and reproduction in any medium, provided the original author and source are credited. 